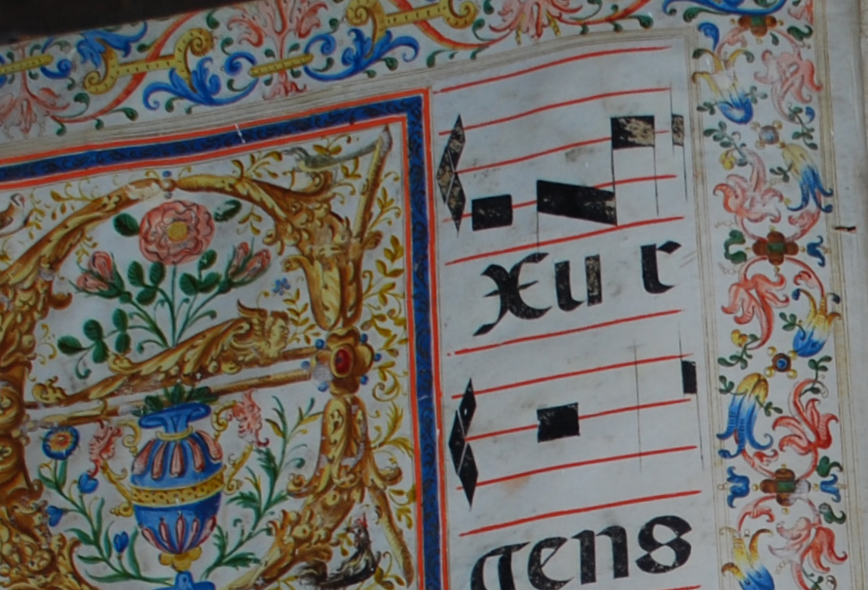

\title{
La huella del ser humano en los libros de coro: creador y destructor cultural
}

\author{
Elena Vázquez Jiménez
}

Resumen: En el patrimonio bibliográfico inciden multitud de agentes externos e internos de degradación. Los libros corales se ven afectados principalmente por unas condiciones ambientales adversas, un almacenamiento inadecuado, o la interrelación de los materiales empleados en su fabricación. Este estudio se basa en el análisis de otra importante causa de degradación que afecta a estos libros: el ser humano. Al realizar una reflexión sobre la relación del hombre con estos libros de gran formato, su historia, su función, su situación y sus causas de degradación, se ha podido comprobar cómo éste se ha convertido en un factor determinante tanto en la preservación como en la desaparición de estos voluminosos libros musicales.

Palabras clave: libros de coro, ser humano, conservación, deterioro

\section{The human action in the books of choir: creator and cultural destructor}

Abstract: In the conservation of the bibliographic heritage, different external and internal degradation factors are involved. In this way, the choral books are mainly affected by the adverse environmental conditions, an-inadequate storage or the chemical interaction of the materials used in their manufacture. This study is focused on the analysis of another important cause of degradation that affects these books: the human action. By reflecting on the relationship of man with these large format books, not only with their history but also with their function, situation and causes of degradation, it has been possible to study how the man's action has become a key factor in both the preservation and the disappearance of these voluminous musical books.

Keyword: choir books, anthropological damage, conservation, deterioration

\section{A ação do ser humano nos livros de coro: criador e destruidor cultural}

Resumo: No património bibliográfico incidem muitos agentes externos e internos de degradação. Os livros de coro são afetados principalmente por condições ambientais adversas, armazenamento inadequado ou pela inter-relação dos materiais empregues no seu fabrico. Este estudo baseia-se na análise de outra importante causa de degradação que afeta estes livros: o ser humano. Ao refletir sobre a relação do homem com estes livros de grande formato, a sua história, a sua função, a sua situação e as suas causas de degradação, foi possível comprovar como este se tornou um fator determinante tanto na preservação quanto no desaparecimento destes volumosos livros musicais.

Palavras-chave: livros de coro, ser humano, conservação, deterioração 
Un pasado glorioso: libros valiosos, libros protegidos

\section{- La creación de cantorales y sus artífices}

Desde su origen, la finalidad primordial de los códices musicales fue la salvaguarda de la pureza de las melodías del repertorio litúrgico, adaptándose durante siglos a las distintas renovaciones del calendario religioso. El lugar de elaboración de estos códices eran los scriptorium medievales, centros donde se copiaban libros tanto para el culto divino como para la enseñanza. Pero a partir del siglo XIII estos centros perdieron la supremacía de elaboración; el oficio evolucionó hacia la secularización debido principalmente al interés de la realeza por la adquisición de colecciones, la creación de las universidades y la compra de libros por parte de la burguesía. Dicha secularización fue causa del desarrollo de actividades mercantiles por parte de los artesanos, labores favorecidas a partir del abaratamiento del soporte. No obstante, en el siglo XV proliferaron en la Península Ibérica grandes centros religiosos de producción de cantorales, al sustituirse los viejos libros de coro manuales y de atril por otros de mayor tamaño para el facistol. En la península, los primeros en llevar a cabo esta labor fueron el scriptorium de la catedral hispalense y el del Monasterio de Guadalupe. Aunque la
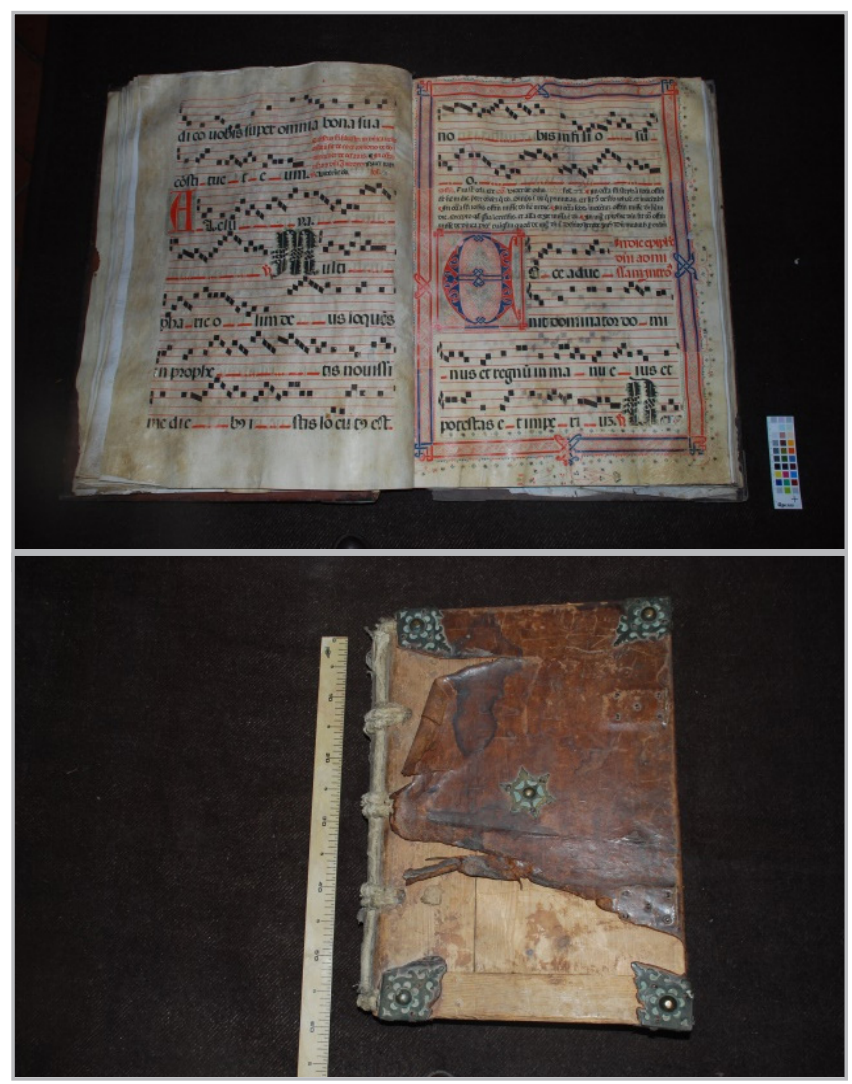

Figura 1.- Vista general del interior (arriba) y exterior (abajo) de un cantoral en el que se puede apreciar la diversidad de materiales y técnicas de elaboración necesarias en su manufactura. Prioral de Santa María (Carmona). producción de los monasterios también llegó a ser muy importante, el mayor volumen de cantorales se realizaba en las catedrales: a la de Sevilla se sumarían primero las de Ávila, Segovia, Toledo y Palencia y más tarde, las de Badajoz, Córdoba, Jaén y Granada (Villaseñor 2011). [figura 1]

El proceso de la elaboración de un libro de coro suponía una labor más compleja que en otros libros debido a su diversidad de contenido y de materiales, y a su gran formato, por lo que normalmente su elaboración era una tarea que recaía en varios autores. Si el trabajo se llevaba a cabo íntegramente dentro del recinto monacal solía ser una tarea comunitaria reglada (uno de los reglamentos conservados es el del Monasterio de Guadalupe de finales del siglo XV). Si la manufactura se llevaba en cambio fuera del ámbito religioso, ésta solía ser de carácter familiar, pudiendo ser varios los oficios involucrados en la elaboración

En el ámbito eclesiástico no todas las órdenes religiosas se encontraban vinculadas con la misma intensidad a la elaboración de cantorales. La orden jerónima es una clara muestra de dedicación: además de en el monasterio de Guadalupe cabe destacar su labor en el Monasterio de Espeja en Soria o en el Convento de Nuestra Señora del Valle en Écija. También existían otras órdenes monásticas con talleres dedicados a la creación y/o restauración de cantorales y en ocasiones se daba la colaboración entre ellas; como ejemplo a mediados del siglo XVII se encuentran los mercedarios y los dominicos en Córdoba, o los jerónimos y los agustinos y probablemente los mercedarios en Granada (Bueno 2012: 155. Anexo digital). A veces también existía la colaboración entre religiosos y seglares, como ocurrió en el Monasterio de Guadalupe [1]. Al respecto, en el Monasterio del Sacromonte de Granada se recoge la existencia de libreros-restauradores: "Item que se aderecen los libros del coro por este librero que ha venido" [2] [figura 2].

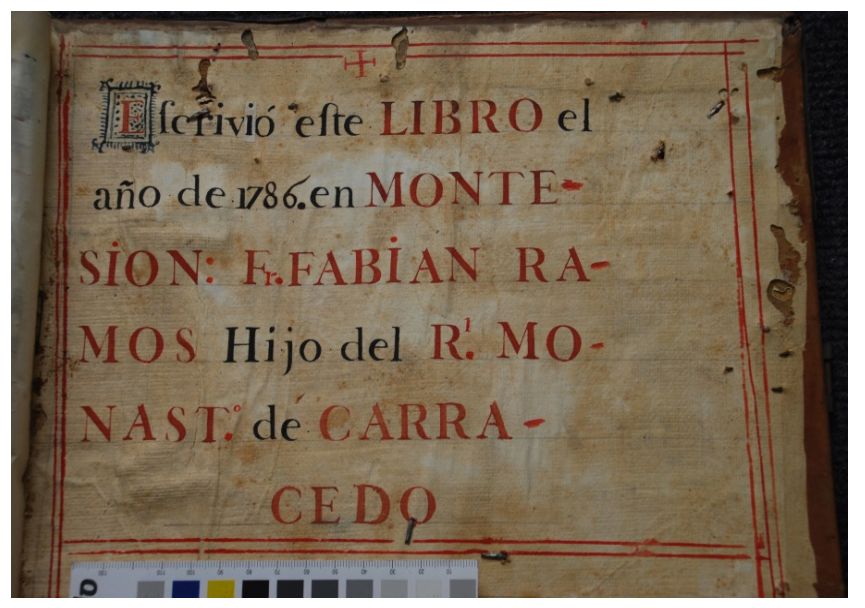

Figura 2.- Referencias de autoría en la contratapa de un cantoral del Palacio de Viana (Córdoba). 


\section{- Medidas de protección: recursos materiales y humanos}

La elaboración de un cantoral suponía un alto coste económico para la institución por lo que era común que se tomasen distintas medidas para su salvaguarda. Era habitual que estos libros estuviesen atados mediante cadenas tanto en el lugar de almacenaje como en el lugar de uso. Aún hoy podemos observar cómo los libros corales del Sacro Monte granadino, por ejemplo, tienen unas argollas en las tapas para colocar cadenas, pudiendo éstas servir además para mantener abierto el volumen. Dependiendo de los recursos particulares de cada institución, el almacenaje también suponía una medida de protección, resolviéndose en algunos casos con un mobiliario sencillo, como armarios, arcas o cajones, y en otros con recursos más elaborados como librerías realizadas ex profeso. Así se fabricaron cuidados sistemas de almacenaje para albergar importantes colecciones de cantorales. El mobiliario del Monasterio de El Escorial, la librería construida en el Monasterio de Yuso (San Millán de la Cogolla) y la realizada en el Colegio Seminario del Corpus Christi (Valencia) son buenos ejemplos de ello. En ellas se cuidaron detalles como el control de la humedad, la ventilación, el ataque biológico o incluso la manipulación (Bueno y Vázquez 2012). Sin embargo, el continuo trasiego de libros durante la liturgia y su gran volumen y peso (algunos cantorales de la colección del Monasterio de Guadalupe tienen incluso pequeñas ruedas para facilitar su transporte) fue motivo para que en algunas instituciones los ejemplares de mayor uso ocuparan lugares provisionales más cercanos al coro, como tumbas cercanas, o incluso se encontraran repartidos por el suelo. Además de estas medidas materiales, en los centros religiosos existía personal encargado de la custodia y cuidado de estos libros (dependiendo de la institución, esta labor podía ser realizada por el chantre, el maestro de capilla, el prior y/o el versiculario).

Así mismo, los cantorales han contado con distintas fórmulas legales de salvaguarda (como la bula emitida por el Papa Nicolás V en 1454, o reglamentos, como el realizado por la Biblioteca Capitular sevillana en el siglo XIX). Para reforzar su defensa y evitar su sustracción, los responsables recurrieron incluso a amenazas de excomunión $^{[3]}$ o a sentencias terribles como la del Monasterio de San Pedro de Barcelona: "Para aquel que robara, cogiera prestado o no retornara un libro a su legítimo propietario, que se transforme en una serpiente su mano y se la desgarre. Que queda paralizado o todos su miembro malditos. Que sufra el dolor pidiendo en voz alta clemencia, y que no se le permita recuperarse de su afonía hasta que se descomponga. Permítase a los gusano de los libros que roan sus entrañas (...) y cuando vaya a alcanzar su castigo final, permítase que se consuma eternamente en las llamas del infierno" (Carreño 2008: 17).

También han existido personas que han actuado en un momento dado anónimamente en pro de la conservación de este patrimonio; en la catedral de Jaén, durante la guerra civil española fueron escondidos sus libros de coro en las bóvedas del templo, y es que, como escribiría posteriormente $\mathrm{M}^{\mathrm{a}}$ Teresa León respecto a la salvaguarda del patrimonio cultural durante esta contienda: "Una cosa fueron las hordas enloquecidas que incendiaron y saquearon templos y conventos, y otra absolutamente distinta esta historia de personas cultivadas y conscientes que contribuyeron a salvar una parte de nuestro tesoro artístico hasta donde llegaron sus fuerzas" (Ara et al. 2009: 526).

Actualmente este patrimonio bibliográfico se encuentra protegido por diversos acuerdos internacionales, la normativa estatal y la autonómica, y por acuerdos entre la Iglesia y el Estado. Afortunadamente, el número de recomendaciones, normativas y aspectos relacionados con la legislación sobre la protección del patrimonio cultural se ha ido afianzando con el tiempo, cumpliendo un papel indispensable para su pervivencia.

\section{La situación actual de los libros de coro}

\section{- Causas de degradación}

Los cantorales son excelentes trasmisores del patrimonio material e inmaterial de una época pasada; son muestra del espíritu creador de artesanos y artistas al aunar en una misma obra la función utilitaria como objeto litúrgico y la función estética. Además, los costosos materiales y elaboradas técnicas empleados en su factura, el interés de los artífices y responsables por su conservación, y el habitual esmero en el cuidado de su entorno, son algunos de los condicionantes que le otorgan por naturaleza durabilidad a lo largo del tiempo. No obstante se han visto afectados por una serie de factores de deterioro (Bueno y Vázquez 2012). Por un lado están los de origen endógeno o interno, como los relacionados con la naturaleza de los distintos elementos que constituyen el libro y con la calidad de los mismos, así como los procesos inadecuados de elaboración, las tintas empleadas, e incluso su gran formato y peso. Y por otro lado los causados por agentes externos de diversa naturaleza: de origen medioambiental (luz, contaminantes atmosféricos, la circulación del aire, temperatura y humedad), biológico (desde microorganismos hasta animales de mayor tamaño) y antrópico.

El hombre ha jugado un papel decisivo en la preservación de los libros de coro; su existencia y estado de conservación se han visto supeditados en gran medida a la civilización para la que fueron creados. Como agente de alteración, el ser humano ha producido una gran variedad de cambios que han modificado parcial o totalmente estos libros, en ocasiones favoreciendo su deterioro y en otras su conservación a través del tiempo. Estas alteraciones se han dividido en tres grupos según la naturaleza de su fuente: las relacionadas con los sucesos sociales (conflictos bélicos, desamortizaciones, robos y saqueos), con su funcionalidad 
(en época de uso fue decisiva para su conservación la frecuencia con la que cada ejemplar era utilizado y las adaptaciones al contenido, y en la época de obsolescencia en cambio influyeron la pérdida de funcionalidad y el olvido) y por último las relacionadas con los siniestros y accidentes (catástrofes imprevisibles como el fuego, riadas e inundaciones). Estas alteraciones han producido una serie de efectos en los cantorales: abandono, conservación, pérdida patrimonial, un almacenamiento inadecuado, numerosos cambios en su ubicación, condiciones medioambientales inadecuadas, comercio tanto secular como religioso, descontextualización, enmiendas, exposiciones inadecuadas, incendios, saqueos, robos, reciclaje de sus hojas, usos inverosímiles, renovaciones de ejemplares, restauraciones y medidas de conservación preventiva).

\section{- Sucesos sociales}

Los conflictos bélicos siguen siendo una gran amenaza patrimonial que causa la pérdida irreparable de innumerables bienes culturales. En este aspecto, los cantorales no han sido más afortunados, siendo abundantes las noticias históricas sobre su repercusión en estos libros; entre algunos ejemplos se encuentran la colección de cantorales de la Catedral de Cádiz, que quedó gravemente dañada por la Armada Inglesa en 1596 (García 2005) y los libros de coro de la Catedral de Albarracín (Teruel) que fueron empleados como parapeto durante la Guerra Civil (alguno de ellos aún conserva los efectos de la metralla). En Valencia el panorama no fue distinto, el Museo Diocesano perdió gran parte de su patrimonio documental y bibliográfico en varias contiendas militares: un incendio durante la Guerra de la Independencia y otro durante la Guerra Civil Española provocaron la pérdida de la mayor parte de su biblioteca y archivo (Vázquez et al. 2012). Otras colecciones corrieron mejor suerte, gran parte de los cantorales del Monasterio de El Escorial fueron salvados durante la invasión francesa trasladándose a
Madrid (Rabanal 1947). Entre las hojas de los cantorales conservados en la Prioral de Carmona (Sevilla) aún pervive la huella del fervor político con llamamientos sobrescritos como "Viva la República". Los daños producidos en los cantorales por estos sucesos son numerosos: agujeros, arañazos, rasgados, cortes, desgastes, manchas y la pérdida de material y de elementos constitutivos. [figura 3]

Los conflictos armados y/o los cambios políticos a menudo han desencadenado otras acciones que han afectado a la conservación del patrimonio, como fueron las desamortizaciones religiosas. En la larga lista de bienes enajenados a la Iglesia durante las distintas desamortizaciones se encuentran algunos cantorales; como ejemplo, en el inventario del coro del Monasterio de los Jerónimos de Espeja (Soria) de 1835 se solicitó la entrega de "treinta y tres cantorales buenos y en pergamino todos" (Rubio 2000: 386). El Monasterio de la Luz (Lucena del Puerto, Huelva) tras su desamortización pasó a convertirse en cortijo de labranza, molino de aceite y bodega, trasladándose sus ornamentos sagrados, entre ellos posiblemente los libros de coro, a la parroquia del pueblo. Aunque en muchos casos este tipo de acciones suponen entre otras consecuencias la descontextualización de los bienes, en ocasiones también suponen la conservación de ejemplares que en otras circunstancias desafortunadas hubiesen posiblemente desaparecido, como es el caso de los cantorales custodiados actualmente en la Biblioteca Nacional de España.

Igualmente, acciones como robos y saqueos se encuentran en constante relación con este patrimonio. La simple riqueza material de estos libros ha sido motivo suficiente para que hoy contemos con numerosos ejemplos; en la Catedral de Pamplona se contrató en 1607 a don Juan de Arana para que restaurase sus libros de coro porque se habían hurtado muchas hojas (Goñi 1946). Inventarios eclesiásticos de otras instituciones recogen referencias parecidas: en uno de 1922 de la Parroquia de San Esteban (Sevilla) se cita la existencia de tres libros de

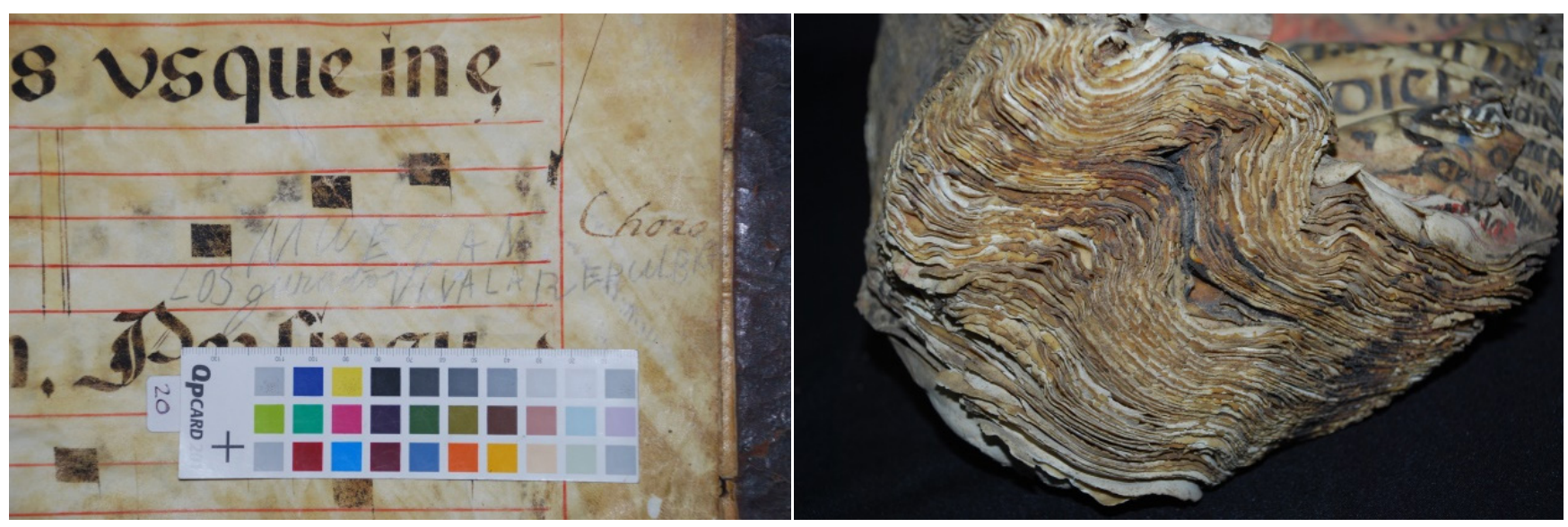

Figura 3.- A la izquierda el detalle del llamamiento a la Republica, Prioral de Santa María de la Asunción (Carmona). A la derecha, detalle de un cantoral afectado por el fuego durante la guerra civil española, Palacio Arzobispal (Valencia). 
coro con faltas de algunas viñetas y en otro de 1930 de la Parroquia del Salvador de la misma ciudad, se recoge que faltaban las viñetas de algunos cantorales por lo que se deduce que fueron robadas (Martín 2004). El caso de la colección del Monasterio de los Jerónimos de Espeja (Soria) no fue distinto: al ser convertido en cárcel tras su desamortización, sus libros de coro se trasladaron al Seminario Santo Domingo de Guzmán (El Burgo de Osma), siendo recortadas gran parte de sus iluminaciones (Rubio 2000). Estas noticias siguen ocurriendo: en 1990 tres cantorales fueron recuperados en un registro producido en una residencia de Visalia (California). Hoy, estos libros procedentes de un robo perpetrado en 1968 en una iglesia o convento sevillano, se encuentran en el Archivo General de Andalucía (Sevilla).

\section{- La funcionalidad}

Los libros de coro fueron creados con un fin litúrgico, por lo que el carácter utilitario ha marcado un antes y un después en su conservación. Sin embargo, las acciones del ser humano relacionadas con el empleo o la falta de uso de los cantorales, han provocado un efecto perjudicial o beneficioso para su pervivencia según cada caso particular.

\section{- Época de uso}

Los libros de coro eran utilizados por las instituciones eclesiásticas de forma asidua tanto en la misa como en el oficio divino. Sin embargo, es necesario tener presente que la frecuencia de uso no siempre fue igual en todos los volúmenes; por ejemplo, el Ordinario de Misa (que contiene las partes fijas de la Misa), el Común de Santos (utilizado para los santos de jerarquía secundaria) y el Ordinario de Oficio (utilizado durante todo el año) se empleaban de forma más asidua que el Propio de Misa, el Propio de Santos o el Propio de Tiempo para el Oficio. Como consecuencia, en aquellos libros con mayor uso se acentuaban los desgastes, el marcaje de hojas, la fatiga mecánica de la encuadernación, los daños por caídas, las quemaduras o incluso otras prácticas como grafitis ${ }^{[4]}$. En muchos casos, para devolver al libro su funcionalidad era necesario recurrir a las enmiendas. Estas intervenciones históricas eran realizadas bajo una práctica artesanal, y en muchos casos eran llevadas a cabo por los propios artífices de los libros. A pesar de ello, si el volumen se encontraba demasiado deteriorado, el criterio de conservación distaba mucho del actual, llegándose a copiar su texto en un nuevo libro y desechándose el antiguo, como así proponía Richard de Bury en su Filobiblión (1340). En este aspecto, la conservación favoreció a aquellos libros de coro con menor frecuencia de uso, sin embargo, la situación fue muy distinta para aquellos volúmenes que cayeron en una falta total de funcionalidad.

Las adaptaciones de contenido (litúrgico, musical y artístico) han influido notablemente en el aspecto actual de estos libros. Teniendo en cuenta el aspecto litúrgico por ejemplo, la bula Quo a novis (9 de julio de 1568) promulgada por Pio $\mathrm{V}$ a partir del Concilio de Trento supuso la realización de grandes enmiendas en los libros de coro al proclamarse el uso de un nuevo breviario. Este texto debía ser adoptado por las iglesias en el plazo de seis meses, excepto en aquellas instituciones religiosas que tenían un Breviario de al menos doscientos años (la reforma del misal fue promulgada, dos años más tarde, mediante la bula Quo primum). Como consecuencia, muchos talleres se vieron desbordados en la tarea de adaptación a la nueva liturgia, entre ellos la Catedral de Sevilla, donde escribanos, raspadores, iluminadores y encuadernadores tuvieron que transformar los libros de coro al Nuevo Rezado Romano (Marchena 1998). Escribanos como por ejemplo Diego Dorta y su hijo, Jerónimo, además de escribir libros para la catedral de Sevilla, también participaron en las adecuaciones litúrgicas realizadas en estos libros a partir de la reforma tridentina (Marchena 1999). En un cantoral de 1506 de la Abadía del Sacro Monte de Granada aún se conservan partes de la liturgia cristiana que desaparecieron tras la reforma tridentina, concretamente Kyries, Gloria in excelsis, tropados y Sanctus acompañados de prosas (Vega 2011). También se produjeron cambios musicales; en la reforma realizada por S. Pio X (1913) con el fin de unificar y reformar el canto gregoriano, se promovió el uso de nuevos libros de canto, y en la Catedral de Pamplona, al no existir ningún oficial que escribiera ya en prima regla (con el nuevo rezado se pasó a escribir en cinco reglas) las labores de enmienda suponían un mayor esfuerzo que el coste de elaborar un ejemplar nuevo (Goñi 1946). Adaptaciones artísticas como el decoro han afectado a la conservación de las iluminaciones realizadas en estos libros. Las conclusiones del Concilio de Trento (Decreto De invocatione, veneratione et reliquiis Sanctorum, et sacris imaginibus, acerca de la invocación, veneración y reliquias de los santos y sobre las imágenes sagradas), afectaron a las representaciones pictóricas religiosas en general creándose una serie de normas e indicaciones iconográficas para los artistas: el dogma católico quedó fijado y el decoro impuesto, siendo ciertas representaciones pictóricas tachadas de demasiado naturalistas o indecorosas.

Las distintas medidas de adaptación de los cantorales a su uso han ocasionado numerosos cambios formales en estos libros. El elevado coste material de estos libros Ilevó a las instituciones, en época de necesidad, al reciclaje de sus hojas y encuadernaciones, dando como resultado cantorales en los que se aprecia el efecto de la guillotina, hojas en las que se ha eliminado parcial o totalmente el contenido. El reciclaje fue una práctica habitual en estos libros reutilizándose hojas completas e incluso las tapas (Bueno 2005). Cuando los cambios de texto eran impracticables, se eliminaban ejemplares completos, como ocurrió en el Monasterio de Guadalupe donde estas hojas en blanco eran guardadas en el scriptorium y sus iluminaciones recicladas para libros posteriores (García 

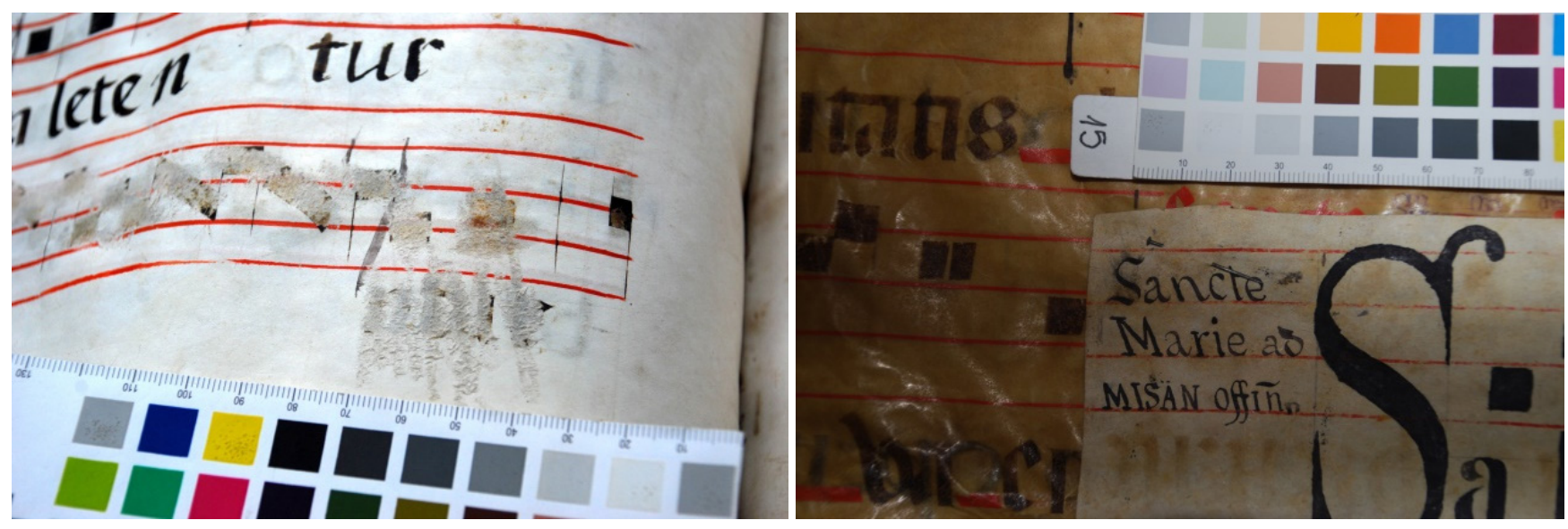

Figura 4.- De izquierda a derecha, ejemplos de adecuaciones realizadas mediante el raspado del pergamino y la colocación de un parche sujeto mediante un alfiler.

1998). Algunas iluminaciones de calidad eran recortadas y cosidas o adheridas en libros más modernos. El reciclaje también ha ocasionado alteraciones en la Ley de Gregory ${ }^{\text {[5] }}$ debido a las ampliaciones, modificaciones y reformas sufridas a lo largo del tiempo. Los cambios de contenido no siempre se han llevado a cabo con suficiente esmero o los recursos necesarios, dando lugar a numerosos tipos de parches de mejor o peor factura, y una gran variedad de soluciones para afrontar la situación. Los parches en los cantorales son de naturaleza variada, con trozos de pergaminos o papel y sin contenido o reciclados, eran cosidos, adheridos o incluso sujetos con alfileres. También es común ver en estos libros textos tachados, emborronados o cubiertos con distintos tipos de pintura de color blanco (Según Marchena (1998) en los cantorales de la Catedral de Sevilla, se conservan hojas pintadas con albayalde o carbonato básico de plomo). [figura 4]

En el caso de realizarse un cambio en el que era necesaria la reencuadernación, el cantoral sufría otra serie de daños que afectaban a su formato; la disminución de tamaño afectaba a aspectos como la proporción áurea, y la mutilación de elementos colocados en las zonas más extremas de las hojas como orlas y numeraciones.

\section{- Época de obsolescencia}

Gran parte de estas colecciones fueron utilizadas hasta mediados del siglo XX, como la colección del Monasterio de El Escorial o la colección de la Abadía del Sacro Monte en Granada. A partir del Concilio Vaticano II y a pesar de ser el canto gregoriano reconocido como el propio de la liturgia romana, la mayoría de estos libros cayeron en desuso; entre otros motivos, la liturgia dejó de celebrarse en latín. La pérdida de significado ha incrementado su desconexión con la sociedad, y ha terminado siendo la causa de alteración de origen antrópico que más ha afectado a estos libros.
Hoy muchos volúmenes son expuestos en unas condiciones descontextualizadas sin tener presentes sus características singulares como libros de gran formato. Es común ver cantorales expuestos con una apertura excesiva, una inadecuada iluminación, en una posición incorrecta o durante un tiempo excesivamente prolongado. [figura 5]

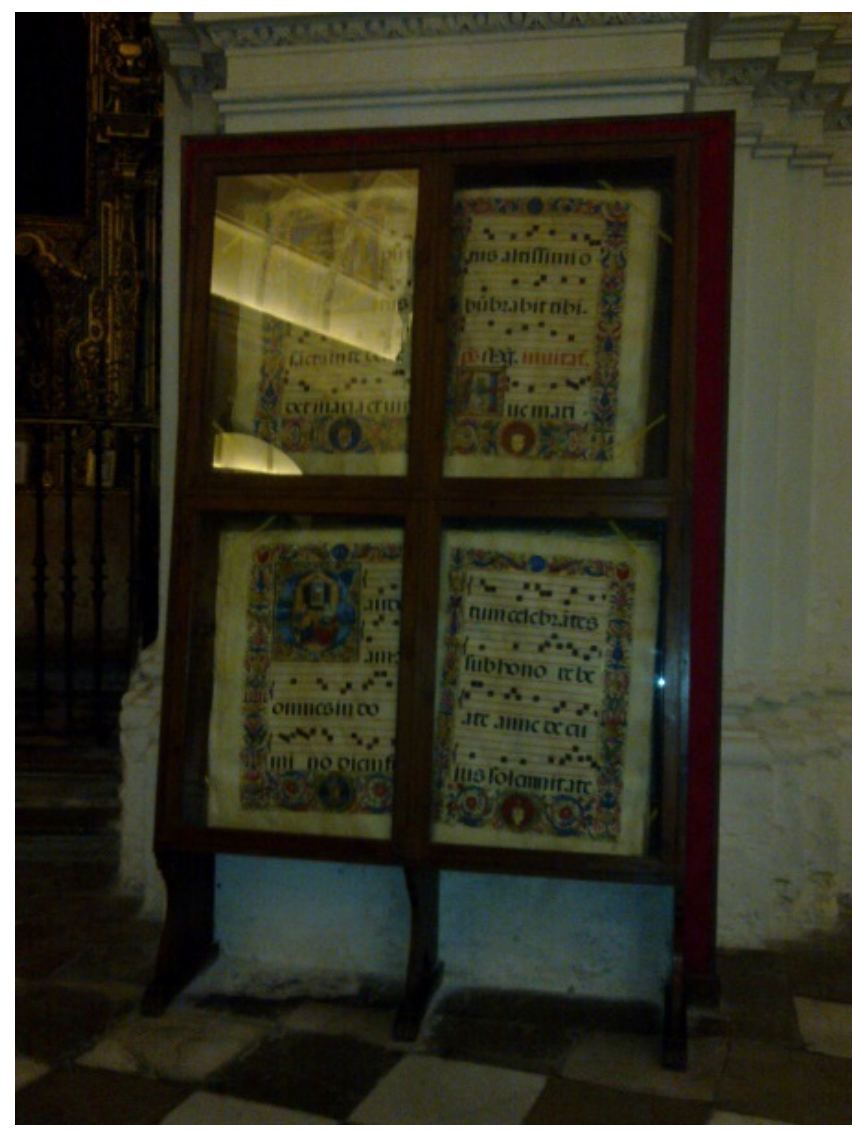

Figura 5.- Cantoral expuesto con una apertura excesiva y en una posición inadecuada. La colocación totalmente en vertical fuerza la estructura del libro y provoca deformación y el descuelgue de sus hojas 
Su falta de significado avivó el valor comercial de su aspecto decorativo en el ámbito secular ${ }^{[6]}$, pasando sus hojas y preciadas iluminaciones a convertirse en objeto de consumo. Aún hoy en día es fácil encontrar en tiendas de antigüedades hojas de cantoral o iluminaciones recortadas y enmarcadas a la venta. Marchena recoge cómo hace años estaban a la venta en la librería Les Enluminures (París) algunas miniaturas probablemente procedentes de libros de coro de la Catedral de Sevilla. En los mercadillos de libros de segunda mano aún se pueden ver hojas sueltas y otros elementos a la venta. A raíz de esta situación existen historias desafortunadas como la venta por internet $\left(\mathrm{eBay}^{\odot}\right)$ de varios fragmentos de los cantorales del Real Monasterio de Santo Tomás en Ávila (Villaseñor 2009 a); de esta colección de finales del siglo XV sólo se conservan nueve hojas (repartidas entre el Museo Arqueológico Nacional de Madrid que posee tres y una colección particular que tiene el resto de hojas), siete letras (dos letras se encuentran en el Fitzwilliam Museum de Cambridge, una en la P. Morgan Library de Nueva York, y el resto en una colección particular). [figura 6]

Fruto de la falta de funcionalidad fue también el olvido, factor que no siempre comporta un aspecto negativo en la conservación (recientemente en la Parroquia de Santa María la Blanca de Villalcázar de Sirga en Palencia fueron descubiertos diez cantorales en una alacena durante labores de limpieza e iluminación de la iglesia), ha sido causa de numerosos efectos negativos en estos libros (ataque biológico, condiciones

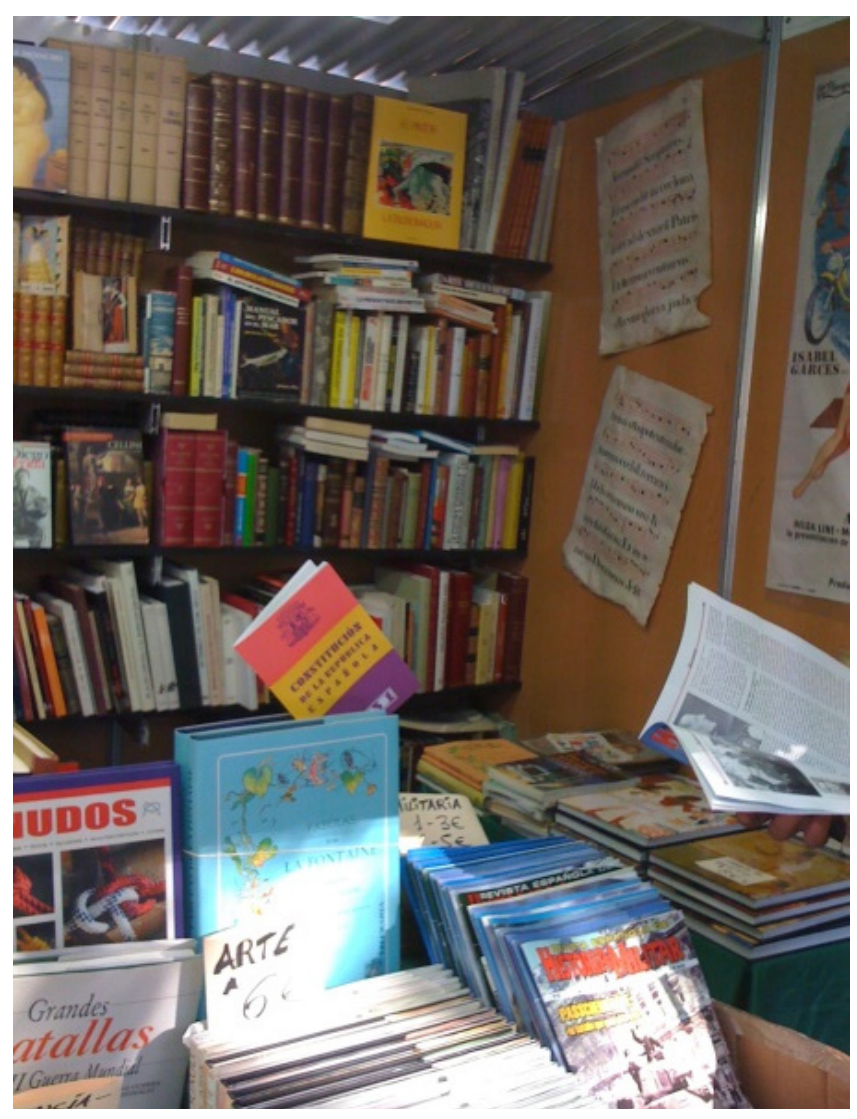

Figura 6.- Hojas de cantoral a la venta en un mercado de libros. ambientales adversas, robos...) al ser muchos de ellos abandonados en condiciones y lugares poco adecuados tras su falta de uso. Es habitual encontrar en su interior objetos ajenos como restos vegetales, papeles desechados e incluso restos de pequeños insectos que, aunque pueden llegar a aportar información sobre la historia social, la historia de su uso o el ámbito al que ha pertenecido el libro ${ }^{[7]}$, con el tiempo y en condiciones adversas de mantenimiento ocasionan daños irreparables en el cantoral.

Esta descontextualización también ha ocasionado que muchas de sus hojas hayan llegado a nuestros días con un fin totalmente distinto para el que fueron creadas. En el Archivo Municipal de Gijón se registran tres fragmentos de antifonarios y cantorales de los cuales dos han pasado a constituir la encuadernación de cartera de un libro de Actas del Consejo del siglo XVII y un tercero fue usado para la realización de la encuadernación de un pequeño libro (que ya no se conserva), que parece ser perteneció al fondo bibliográfico de la familia Jovellanos (Núñez 1995). En la exposición sobre Encuadernaciones Artísticas en el Archivo de la Nobleza (2010) se expuso una hoja de cantoral de pergamino del siglo XIV empleada como cuadernillo de un documento real del siglo XV. Los usos de estas hojas han sido de lo más inverosímiles; las hojas de una veintena de cantorales realizados por Diego Dorta para la Iglesia Colegial de El Salvador (Sevilla), al pasar a formar parte del seminario del Palacio de San Telmo pasaron a servir para confeccionar lámparas. Posteriormente éstas fueron vendidas a un anticuario sevillano, para poco después y tras haber aumentado su valor monetario, salir al extranjero (Marchena 1999). En internet aún es posible la adquisición de hojas de cantoral en forma de pantalla de lámpara.

\section{- Siniestros y accidentes}

Intencionado o fortuito, y en relación o no con otras acciones humanas como los conflictos bélicos, son abundantes los ejemplos de importantes colecciones bibliográficas, no sólo de cantorales, perdidas así en archivos, bibliotecas y centros religiosos por los efectos del fuego. Como ejemplo podemos mencionar el Alcázar de Madrid cuyo incendio el veinticinco de diciembre de 1734 destruyó una gran cantidad de Bienes Patrimoniales, entre ellos su colección de cantorales (Junquera 1965). En muchas ocasiones la recuperación del contenido de las hojas afectadas por el fuego resulta imposible al haberse producido una desnaturalización del colágeno ${ }^{[8]}$, y el grado de reversibilidad depende en gran medida de la estabilidad química del material. En estas hojas se produce una deformación física (producida como consecuencia de la elevada temperatura) y las zonas más expuestas al fuego suelen quedar adheridas debido a las sustancias adhesivas resultantes de este proceso de desnaturalización del colágeno. En algunos casos, en correspondencia con las deformaciones del soporte, también se pueden producir desprendimientos, ondulaciones y pulverización de la capa pictórica debido a las contracciones del material. A menudo el daño se acrecienta por los efectos del agua durante las labores de salvamento. Las riadas e inundaciones provocan 
Tabla 1.- Hojas de cantoral a la venta en un mercado de libros.

\section{ALTERACIONES PRODUCIDAS POR EL FACTOR ANT'RÓPICO EN LOS LIBROS DE CORO}

\begin{tabular}{|c|c|c|}
\hline CAUSAS & EFECTOS & DAÑOS FORMALES \\
\hline \multicolumn{3}{|l|}{ SUCESOS SOCIALES } \\
\hline $\begin{array}{l}\text { CONFLICTO } \\
\text { BÉLICO }\end{array}$ & $\begin{array}{l}\text { - ALMACENAMIENTO INADECUADO } \\
\text { - CAMBIO DE UBICACIÓN } \\
\text { - COMERCIO (SECULAR) } \\
\text {-INCENDIO } \\
\text { - OTROS USOS } \\
\text { - PÉRDIDA PATRIMONIAL } \\
\text {-SAQUEO/ROBO } \\
\text { - VANDALISMO }\end{array}$ & \multirow{3}{*}{$\begin{array}{l}\text { - AGUJEROS/ PÉRDIDA PARCIAL } \\
\text { - ARAÑAZOS/ RASGADOS } \\
\text { - PLIEGUES/ ARRUGAS } \\
\text { - CORTES } \\
\text { - ONDULACIONES/ DEFORMACIONES } \\
\text { - VARIEDAES DE MANCHAS } \\
\text { - ELEMENTOS DESAPARECIDOS } \\
\text { / SIN FUNCIÓN } \\
\text { - ELEMENTOS AJENOS A LA OBRA } \\
\text { - ALTERACIONES EN ELEMENTOS } \\
\quad \text { SUSTENTADOS }\end{array}$} \\
\hline $\begin{array}{l}\text { DESAMORTIZACIÓN } \\
\text { RELIGIOSA }\end{array}$ & $\begin{array}{l}\text { - ABANDONO/ CONSERVACIÓN } \\
\text { - CAMBIO DE UBICACIÓN } \\
\text { - COMERCIO (SECULAR) } \\
\text { - DESCONTEXTUALIZACIÓN } \\
\text { - OTROS USOS } \\
\text { - PÉRDIDA PATRIMONIAL } \\
\text { - SAQUEO/ROBO } \\
\text { - VANDALISMO } \\
\text { - COMERCIO (RELIGIOSO) }\end{array}$ & \\
\hline ROBO & $\begin{array}{l}\text { - CAMBIO DE UBICACIÓN } \\
\text { - DESCONTEXTUALIZACIÓN } \\
\text {-OTROS USOS } \\
\text {-PÉRDIDA PATRIMONIAL }\end{array}$ & \\
\hline
\end{tabular}

\section{FUNCIONALIDAD}

\begin{tabular}{|c|c|c|}
\hline \multicolumn{3}{|l|}{ ÉPOCA DE USO: } \\
\hline $\begin{array}{l}\text { FRECUENCIA DE } \\
\text { USO }\end{array}$ & $\begin{array}{l}\text { - ABANDONO/ CONSERVACIÓN } \\
\text { •ENMIENDAS } \\
\text { • COMERCIO (RELIGIOSO) }\end{array}$ & \multirow{2}{*}{$\begin{array}{l}\text { - AGUJEROS } \\
\text { - VARIEDAD DE COSIDOS } \\
\text { - GUILLOTINADO } \\
\text { - ALTERACIÓN DE LA LEY DE GREGORY } \\
\text { PARCHES }\end{array}$} \\
\hline $\begin{array}{l}\text { ADAPTACIONES DE } \\
\text { CONTENIDO }\end{array}$ & $\begin{array}{l}\text { - CONSERVACIÓN } \\
\text { - ENMIENDAS } \\
\text { - PÉRDIDA PATRIMONIAL } \\
\text { - RECICLAJE } \\
\text { - COMERCIO (RELIGIOSO) }\end{array}$ & \\
\hline \multicolumn{3}{|l|}{$\begin{array}{l}\text { ÉPOCA DE } \\
\text { OBSOLESCENCIA: }\end{array}$} \\
\hline $\begin{array}{l}\text { PÉRDIDA DE } \\
\text { SIGNIFICADO }\end{array}$ & $\begin{array}{l}\text { - ABANDONO } \\
\text { - ALMACENAMIENTO INADECUADO } \\
\text { - ATAQUE BIOLÓGICO } \\
\text { - CAMBIO DE UBICACIÓN } \\
\text { - COMERCIO (SECULAR) } \\
\text { - CONDICIONES } \\
\text { MEDIOAMBINTALES ADVERSAS } \\
\text { - DESCONTEXTUALIZACIÓN } \\
\text { - EXPOSICIÓN INADECUADA } \\
\text { - OTROS USOS } \\
\text {-PÉRDIDA PATRIMONIAL } \\
\text { - SAQUEO/ ROBO } \\
\text { - VANDALISMO } \\
\text { - COMERCIO (RELIGIOSO) }\end{array}$ & \multirow[t]{2}{*}{$\begin{array}{l}\text { - } \text { AGUJEROS } \\
\text { - } \text { ARAÑAZOS/ RASGADOS } \\
\text { PLIEGUES/ ARRUGAS } \\
\text { - } \text { OORTES } \\
\text { - DESGAACIONES/ DEFORMACIONES } \\
\text { - VARIEDAD DE MANAOS } \\
\text { - ELEMENTOS DESAPARECIDOS } \\
\text { / SIN FUNCIÓN } \\
\text { - ELEMENTOS AJENOS A LA OBRA } \\
\text { - ALTERACIONES EN ELEMENTOS } \\
\quad \text { SUSTENTADOS }\end{array}$} \\
\hline OLVIDO & $\begin{array}{l}\text { - ABANDONO/ CONSERVACIÓN } \\
\text { - ATAQUE BIOLÓGICO } \\
\text { - COMERCIO (SECULAR) } \\
\text { - CONDICIONES MEDIAMBIENTALES } \\
\text { ADVERSAS } \\
\text { - DESCONTEXTUALIZACIÓN } \\
\text { - OTROS USOS } \\
\text { - PÉRDIDA PATRIMONIAL } \\
\text { - SAQUEO/ ROBO } \\
\text { - VANDALISMO }\end{array}$ & \\
\hline
\end{tabular}




\begin{tabular}{|c|c|c|}
\hline $\begin{array}{l}\text { SINIESTROS } \\
\text { / ACCIDENTES }\end{array}$ & & \\
\hline INCENDIO & \multirow{3}{*}{$\begin{array}{l}\text {-PÉRDIDA PATRIMONIAL } \\
\text { - CONDICIONES MEDIAMBIENTALES } \\
\text { ADVERSAS } \\
\text { - RENOVACIÓN/ SUSTITUCIÓN } \\
\text { - RESTAURACIÓN } \\
\text { - MEDIDAS DE CONSERVACIÓN } \\
\text { PREVENTIVA }\end{array}$} & \multirow{3}{*}{$\begin{array}{l}\text {-AGUJEROS/ PÉRDIDA PARCIAL } \\
\text { - ARAÑAZOS Y RASGADOS } \\
\text { - PLIEGUES Y ARRUGAS } \\
\text { - CORTES } \\
\text { • ONDULACIONES/ DEFORMACIONES } \\
\text { - DESGASTES Y RASPADOS } \\
\text { - VARIEDAD DE MANCHAS } \\
\text { - ELEMENTOS DESAPARECIDOS } \\
\text { / SIN FUNCIÓN } \\
\text {-ELEMENTOS AJENOS A LA OBRA } \\
\text { - ALTERACIONES EN ELEMENTOS } \\
\text { SUSTENTADOS }\end{array}$} \\
\hline INUNDACIÓN & & \\
\hline $\begin{array}{l}\text { OTRAS } \\
\text { CATÁSTROFES } \\
\text { NATURALES }\end{array}$ & & \\
\hline
\end{tabular}

que los documentos sufran una gran absorción de agua (se produce un aumento del tamaño de la madera, el papel y el pergamino; puede llegar a gelatinizar a este último y favorece el ataque de microorganismos), fuertes presiones físicas, oxidación de elementos metálicos y manchas de lodo y barro, que en ocasiones conllevan su destrucción total (Sánchez 1999). [Tabla 1]

\section{Conclusiones}

En la bibliografía especializada se han analizado las causas internas o externas de degradación en estos libros; al examinar estos agentes de alteración, en muchas ocasiones controlables mediante la acción humana (como es el caso del factor biológico o el medioambiental), podemos concluir cómo el factor antrópico junto a la imparable huella del paso del tiempo y la naturaleza constitutiva de los materiales, constituyen uno de los principales detonantes del estado de deterioro que sufren muchos cantorales, y un agente decisivo para su pérdida o conservación.

El ser humano fabricó este bello patrimonio como contenedor de un mensaje al servicio de la liturgia cristiana. En la búsqueda de la preservación de su contenido, lo protegió con materiales de calidad, empleó estudiadas técnicas de elaboración que puso en manos de exquisitos artesanos, y se tomaron los medios necesarios en pro de su conservación (personal encargado de su custodia, búsqueda de soluciones materiales y legales de seguridad, y un entorno muy cuidado). El resultado fue una prolífera producción de libros de canto que se mantuvo en auge durante siglos. No obstante, y aunque durante su época de uso los libros de coro sufrieron numerosas adaptaciones en su contenido (liturgia, música y decoración), renovaciones, y enmiendas destinadas a su reutilización (se mantuvo su uso hasta principios del siglo $\mathrm{XX}$, momento en el que la iglesia optó por la simplificación de los ritos y llevó a cabo reformas litúrgicas), su conservación estuvo asegurada, al ser valorados estética, funcional y simbólicamente. Hoy se hace aún más patente la necesidad de incrementar los esfuerzos en su conservación ya que siguen manteniendo su valor, conservando su belleza y atractivo, y constituyendo una fuente importante de información al ser una representación especialmente singular de nuestro pasado. Aunque acontecimientos sociales como guerras, desamortizaciones y continuos robos, han mermado considerablemente este patrimonio a lo largo de nuestra Historia, la falta de funcionalidad acrecentó el comercio, su descontextualización y su desconexión con el pueblo. Con el tiempo la ruptura de lazos entre el individuo y este patrimonio ha ido en aumento, lo que supone una amenaza para su conservación.

\section{Notas}

[1] Además de la formación de religiosos para la elaboración de estos libros, se contaba, como en muchos otros talleres monásticos, con el apoyo de artesanos seglares, distinguiéndose así entre el oficio denominado de dentro, desarrollado por los religiosos y el oficio de fuera, realizado por artesanos y artistas externos (Villaseñor 2009 b).

[2] Libro de Cabildos No6. 8-mayo-1697, Folio 86 recto Bis. (Bueno 2012: Apéndice Documental 96. Anexo digital).

[3] El prior de Santa María de la Vega (Salamanca) y encargado de la custodia de los libros dio un ultimátum de veinticuatro horas para devolver los libros que habían desaparecido bajo pena de excomunión (Suárez 2005: 227)

[4] Se ha empleado este término para denominar las inscripciones, rayados o dibujos presentes en la superficie de las hojas y tapas de los cantorales. Los grafitis, que aparecen con bastante frecuencia en estos libros, pueden dividirse en dos grupos: las anotaciones, normalmente manuscritas con instrucciones para un libro concreto (uso, recomendaciones respecto al texto, firmas, comentarios diversos...) y dibujos o grafías de lo más variadas. Aunque en ocasiones suponen agresiones para la obra muchas de ellas contienen información importante sobre el entorno de la misma, por lo que se opta por su conservación.

[5] Debido al cambio de tonalidad entre las dos caras del pergamino (pars pili o exterior más amarillenta, y pars munda o interior más blanca) y por cuestiones estéticas, al encartar las hojas de los cuadernillos de los libros, se buscaba que las caras enfrentadas de las hojas fuesen del mismo tono. A este principio se le conoce como el nombre de principio o Ley de Gregory. En las enmiendas y reconstrucciones realizadas en los cantorales no siempre se ha tenido en cuenta este principio, rompiéndose la alternancia de tono en el nuevo montaje del volumen. 
[6] Algunas instituciones eclesiásticas compraban los cantorales que otras desechaban por renovación (De Vicente 2010) o provenientes de aquellas instituciones religiosas desamortizadas, cerradas o en las que ya no se cantaba.

[7] En una intervención sobre los cantorales del Colegio Seminario Corpus Christi en el Instituto Valenciano de Conservación, los restos desechados de los cantorales intervenidos se encapsularon en bolsas realizadas con tereftalato de polietileno (Melinex ()) transparente para una vez finalizada la restauración del volumen almacenarla junto al ejemplar en una caja de cartón permanente.

[8] El calentamiento del colágeno produce su desnaturalización, siendo su primera consecuencia un enorme acortamiento de las fibras. Este acortamiento se produce a una temperatura característica para el colágeno de cada especie animal. También se destruye la estructura de triple hélice. La temperatura a la que se desnaturaliza el colágeno depende del contenido de prolina e hidroxiprolina: A mayor contenido, mayor es la temperatura necesaria.

\section{Bibliografía}

ARA, J.; ARGERICH I. y BRUQUETAS R. (2009). “El salvamento del tesoro artístico español durante la guerra civil y sus principales protagonistas". En Actas de las XIV Jornadas Internacionales de Historia del arte. Arte en tiempos de guerra, Madrid: CSIC, 525-537.

BUENO, J. (2005). "La encuadernación de los libros de coro: las cubiertas de los cantorales de la Abadía del Sacromonte de Granada", Boletín del Instituto Andaluz del Patrimonio Histórico, 53: 58-69.

BUENO, J.; VÁZQUEZ, E. (2012). “Los libros de coro y las principales causas extrínsecas de su deterioro", Ge- conservación, 3: 69-88.

BUENO, J. (2012). Los libros de coro en pergamino e ilustrados de la Abadía del Sacro Monte de Granada: estudios y conservación. Granada: U. Granada.

CALVO, M. "Colágeno", en Bioquímica de los alimentos. Milk Science, Universidad de Zaragoza. http://milksci.unizar.es/bioquimica/ temas/proteins/colageno.html [Consulta: 8/11/2017].

CARREÑO, E. (2008). Marcas de propiedad en los libros novohispanos. México D.F.: Apoyo al Desarrollo de Archivos y Bibliotecas de México.

DE VICENTE, A. (2010). Los cargos musicales y las capillas de música en los monasterios de la orden de San Jerónimo (siglos XVI-XIX). Tesis doctoral, Universidad Complutense de Madrid, España.

GARCíA, J.A. (2005). "Los libros corales de la Catedral de Cádiz" Historia, Instituciones, documentos, 32: 145-174.

GARCÍA, FR. S. (1998). Los miniados de Guadalupe. Catálogo y museo. Sevilla: Ediciones Guadalupe.

GOÑI, J. (1946). “La adopción de la liturgia tridentina y los libros de coro de la Diócesis de Pamplona", Príncipe de Viana, 24: 565571.
JUNQUERA, P. (1965). "Los libros de coro de la Real Capilla" Reales Sitios, 6: 12-27.

MARCHENA, R. (1999). "Diego Dorta en la catedral de Córdoba", Laboratorio de Arte, 12: 79-91.

MARCHENA, R. (1998). Las miniaturas de los libros de coro de la catedral de Sevilla: el siglo XVI. Sevilla: Secretariado de Publicaciones.

MARTíN, A. (2004). Sillerías de coro de Sevilla. Análisis y evolución. Sevilla: Guadalquivir.

NÚÑEZ, E. (1995). "Fragmentos de antifonarios y cantorales litúrgicos del Archivo Municipal de Gijón. Actas del IX Congreso de la Asociación de Archiveros de la Iglesia de España", Memoria Ecclesiae, segunda parte, 7: 493-497.

RABANAL, V. (1947). Los cantorales de El Escorial. El Escorial: Monasterio de El Escorial.

RUBIO, M (2000). "Cantorales gregorianos del Monasterio de los Jerónimos de Espeja (Soria)". En XIV Centenario Diócesis de Osma: Premios de investigación. Soria: Diputación Provincial de Soria, 369-424.

SÁNCHEZ, A (1999). Políticas de conservación en bibliotecas. Madrid: Arco/libros.

SUÁREZ, A (2005). "El patrimonio bibliográfico comunitario de Santa María de la Vega (Salamanca) en 1577", Estudios humanísticos, Filología, 27:209-232.

VÁZQUEZ, E; BUENO, J; MUÑOZ, A. (2012). “Memoria histórica o recuperación: ¿qué podemos hacer ante un libro consumido por el fuego?". En Actas del $6^{\circ}$ Congreso Internacional Virtual Turismo y Desarrollo, Málaga: Universidad de Málaga, 1-14.

VEGA, Ma. J. (2011). “Música inédita en la Abadía del Sacro Monte de Granada". En Nuevas aportaciones al conocimiento y estudio del Sacro Monte, VEGA, M.J.; GARCÍA, M.L.; LÓPEZ, A. (coords.). Granada: Fundación Euroárabe, Cátedra Al-Babtain, 47-69.

VILLASEÑOR, F. (2009 a). "Los libros de coro del Real Monasterio de Santo Tomás de Ávila", Reales sitios, 180: 4-27.

VILLASEÑOR, F. (2009 b). "Los iluminadores en Castilla durante el siglo XV: consideración socioeconómica y particularidades del oficio", De arte, 8:27-46.

VILLASEÑOR, F. (2011). "Ensayando estorias grandes y letras cabdinales", Goya, 334:74-87. 


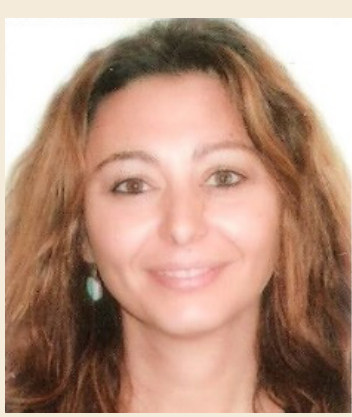

\section{Elena Vázquez Jiménez}

evazquez5@us.es

Facultad de Bellas Artes, Universidad de Sevilla

Doctora en Bellas Artes en la especialidad de Conservación y Restauración de Bienes Culturales por la Universidad de Sevilla. Especialista en conservación y restauración de documento gráfico y tejidos. En el campo de la investigación ha recibido una beca de posgrado de carácter internacional, realizada en México D.F., y otra de ámbito nacional a través de la Fundación de Investigación de la Universidad de Sevilla. Ha realizado dos estancias de investigación en el Instituto Valenciano de Conservación Restauración en el Departamento de Obra Gráfica y Material de Archivo. Asimismo ha participado en varios proyectos de investigación y ha asistido a más de una docena de congresos, jornadas y seminarios de carácter tanto local, nacional como internacional, coordinando y participando con diversas aportaciones en muchos de ellos.

Actualmente es profesora sustituta interina del Departamento de Pintura de la Facultad de Bellas Artes de la Universidad de Sevilla.

\section{Artículo enviado el 29/11/2017 \\ Artículo aceptado el 07/05/2018}

